\title{
An Energy-Based Body Temperature Threshold between Torpor and Normothermia for Small Mammals
}

\author{
Craig K. R. Willis* \\ Department of Biology and Centre for Forest \\ Interdisciplinary Research, University of Winnipeg, 515 \\ Portage Avenue, Winnipeg MB R3B 2E9, Canada
}

Accepted 4/13/2007; Electronically Published 9/5/2007

\begin{abstract}
Field studies of use of torpor by heterothermic endotherms suffer from the lack of a standardized threshold differentiating torpid body temperatures $\left(T_{\mathrm{b}}\right)$ from normothermic $T_{\mathrm{b}}$ 's. This threshold can be more readily observed if metabolic rate (MR) is measured in the laboratory. I digitized figures from the literature that depicted simultaneous traces of $\mathrm{MR}$ and $T_{\mathrm{b}}$ from 32 respirometry runs for 14 mammal species. For each graph, I quantified the $T_{\mathrm{b}}$ measured when MR first began to drop at the onset of torpor $\left(T_{\mathrm{b}-\text { onset }}\right)$. I used a general linear model to quantify the effect of ambient temperature $\left(T_{\mathrm{a}}\right)$ and body mass $(\mathrm{BM})$ on $T_{\mathrm{b} \text {-onset. }}$. For species lighter than $70 \mathrm{~g}$, the model was highly significant and was described by the equation $T_{\mathrm{b} \text {-onset }}=(0.055 \pm 0.014) \mathrm{BM}+$ $(0.071 \pm 0.031) T_{\mathrm{a}}+(31.823 \pm 0.740)$. To be conservative, I recommend use of these model parameters minus 1 standard error, which modifies the equation to $T_{\mathrm{b} \text {-onset }}-1 \mathrm{SE}=(0.041) \mathrm{BM}+$ $(0.040) T_{\mathrm{a}}+31.083$. This approach provides a standardized threshold for differentiating torpor from normothermia that is based on use of energy, the actual currency of interest for studies of torpor in the wild. Few laboratory studies have presented the time-course data required to quantify $T_{\mathrm{b} \text {-onset }}$, so more data are needed to validate this relationship.
\end{abstract}

\section{Introduction}

Heterothermy, or torpor, is fundamental to the lives of many endotherms, and there is continued interest in quantifying its use in the laboratory and field (e.g., Geiser 2004; Solick and Barclay 2006; Willis et al. 2006). Torpid animals save large amounts of energy by lowering their body temperature $\left(T_{\mathrm{b}}\right)$ set

*E-mail: c.willis@uwinnipeg.ca.

Physiological and Biochemical Zoology 80(6):643-651. 2007. (C) 2007 by The University of Chicago. All rights reserved. 1522-2152/2007/8006-6157\$15.00 DOI: $10.1086 / 521085$ point and abandoning metabolic heat production until $T_{\mathrm{b}}$ falls to the new, reduced set point. The IUPS Thermal Commission (2003, p. 102; after Bligh and Johnson 1973) defines torpor as "a state of inactivity and reduced responsiveness to stimuli (e.g., during hibernation, hypothermia, or estivation)." However, there is growing appreciation that, in terms of its importance for ecology and evolution, torpor is better defined by its implications for energy savings owing to reduced heat production than by some level of behavioral responsiveness. Many endotherms are still active and capable of performing demanding activities (including flight) at levels of metabolic heat production and $T_{\mathrm{b}}$ low enough to result in large energy savings (between $20^{\circ}$ and $30^{\circ} \mathrm{C}$; Augee 1969; Austin and Bradley 1969; Bradley and O'Farrell 1969; Hirshfeld and O'Farrell 1976; Willis and Brigham 2003). The phrase "reduced responsiveness" in the definition is particularly subjective and, thus, not useful for quantifying a difference between torpor and homeothermy. Consider that torpid animals respond to disturbance by arousing from torpor, even at the lowest values of $T_{\mathrm{b}}$ (Geiser 2004). The magnitude of these responses can be enormous if changes in $T_{\mathrm{b}}$ or metabolic rate (MR) are appropriately considered responses. These problems with the traditional definition of torpor, and the fact that different categories of heterothermy are recognized, have prompted the use of new terminology to describe energy-saving heterothermy in general (e.g., facultative heterothermic responses; McKechnie and Lovegrove 2002). For simplicity, in this article I define "torpor" as an energy-saving state of heterothermy during which metabolic heat production and $T_{\mathrm{b}}$ are below normal (i.e., normothermic or homeothermic) levels.

Many laboratory studies rely on open-circuit respirometry for indirect measurement of MR. Time courses recorded during these trials reveal obvious and abrupt declines in MR at the onset of torpor. Thus, in laboratory studies, in addition to overall energy savings, it is relatively easy to quantify temporal patterns (bout duration, time of onset) and magnitude (change in MR) of torpor under different conditions because the start and end of each torpor bout are obvious from the MR trace. Confinement in a metabolic chamber is not a natural circumstance for any species, so MR data, while valuable, are limited in terms of what they reveal about use of torpor in the wild (Willis and Cooper, forthcoming). A growing number of studies use temperature-sensitive transmitters or dataloggers to record $T_{\mathrm{b}}$ or skin temperature $\left(T_{\mathrm{sk}}\right)$ in freeliving animals (Körtner and Geiser 2000; Lausen and Barclay 2003; Turbill et al. 2003; Dietz and Kalko 2005; Munro et al. 
2005; Solick and Barclay 2006; Turbill 2006) or under seminatural conditions in laboratory enclosures (Song et al. 1998a; Schmid 2000; Cooper and Withers 2004; Willis et al. 2005a). As in the laboratory, these studies often aim to quantify temporal patterns and magnitude of torpor bouts because these variables affect energy balance with implications for reproductive fitness. A persistent challenge, however, is defining some $T_{\mathrm{b}}$ or $T_{\mathrm{sk}}$ threshold to differentiate torpor from normothermia in the absence of metabolic data. Such a threshold is essential if depth and duration of torpor bouts are to be calculated, but the subjective nature of the traditional definition for torpor (IUPS Thermal Commission 2003) has led to uncertainty about how it should be quantified.

Barclay et al. (2001) identified more than 20 values of $T_{\mathrm{b}}$ and $T_{\text {sk }}$ used to define torpor bouts in the literature, as well as other definitions based on criteria such as $T_{\mathrm{b}}-T_{\mathrm{a}}$ differentials or behavior, but few of these were derived with any physiological justification. The most popular value used in studies reviewed by Barclay et al. (2001) was a conservative (though no less arbitrary) $30^{\circ} \mathrm{C}$. A conservative threshold is important to avoid overestimating use of torpor, but a potential consequence of being overly exclusive is the failure to detect shallow torpor bouts. Because of $\mathrm{Q}_{10}$ effects, torpor is characterized by diminishing energetic savings as $T_{\mathrm{b}}$ falls (Geiser 2004). Thus, shallow bouts are likely to be of great ecological and evolutionary importance because they result in large energy savings while potentially mitigating the selective costs of torpor, such as vulnerability to predation, reduced growth rate, and delayed reproduction.

Barclay et al. (2001) proposed an important step toward a standardized threshold with their concept of active temperature $\left(T_{\text {act }}\right)$. Active temperature is measured when an individual under study is known to be behaviorally active. For the studies of bats discussed by Barclay et al. (2001), this means recording $T_{\mathrm{sk}}$ or $T_{\mathrm{b}}$ immediately before dusk emergence each night of a study and then, to be conservative, defining $T_{\text {act }}$ (the threshold temperature) as the lowest dusk emergence $T_{\text {sk }}$ or $T_{\mathrm{b}}$ value recorded for an individual during the study (Barclay et al. 2001). The approach could also be applied to dusk emergence of nocturnal, fossorial mammals or morning observations of diurnal birds. While this improves on past practice of arbitrarily selecting a threshold temperature, $T_{\text {act }}$ does have potential limitations. Most important, as mentioned above, many heterothermic endotherms can be active while still saving energy because of a reduced $T_{\mathrm{b}}$ set point (Augee 1969; Austin and Bradley 1969; Bradley and O'Farrell 1969; Hirshfeld and O'Farrell 1976; Willis and Brigham 2003; Willis and Cooper, forthcoming). Therefore, there is little energetic justification for linking the threshold temperature with behavior. Furthermore, $T_{\text {act }}$ cannot account for variation in $T_{\mathrm{b}}-T_{\mathrm{a}}$, and especially $T_{\text {sk }}-T_{\mathrm{a}}$, differentials that can occur even during normothermia, for animals exposed to different $T_{\mathrm{a}}$ 's at the time when $T_{\text {act }}$ is defined (Withers 1992; Willis and
Brigham 2003; Geiser 2004). For example, if $T_{\mathrm{a}}$ happens to be especially low one evening, the $T_{\text {act }}$ threshold may be set very low for an animal measured that night, and as a result, ecologically important shallow bouts of torpor would go undetected for that individual. Torpor patterns of individuals for which $T_{\text {act }}$ was not determined on the cold evening would not be comparable.

McKechnie et al. (2007) proposed an innovative alternative for defining the torpor threshold based on frequency distributions of $T_{\mathrm{b}}$ or $T_{\mathrm{sk}}$ measurements in their field study of freckled nightjars (Caprimulgus tristigma). Their method depends on the premise that the distribution of $T_{\mathrm{b}}$ measurements for a heterothermic endotherm should fit a multimodal pattern (i.e., with one or more torpid peaks and one normothermic peak). The lower tail of the normothermic distribution and the upper tail of the torpor distribution will overlap and conceal each other, especially if shallow torpor is used frequently, but McKechnie et al. (2007) addressed this by assuming that normothermic $T_{\text {sk }}$ measurements were normally (i.e., symmetrically) distributed about the upper modal value. Based on this assumption, they fitted a bell-shaped curve to $T_{\mathrm{b}}$ data for each nightjar, using the shape of the upper half of the distribution (i.e., values greater than the upper modal peak) to infer the shape of the lower half. Values below the lower $99 \%$ confidence limit of the fitted distribution were then considered to reflect use of torpor (McKechnie et al. 2007). This method is clearly more systematic than selecting an arbitrary temperature and is appealing for several reasons. First, the curve can be fitted with $99 \%$ confidence based solely on the normothermic modal and maximum $T_{\mathrm{b}}$ 's recorded for each individual as long as maximum $T_{\mathrm{b}}$ is assumed to reflect the upper $99 \%$ confidence limit for the distribution (Zar 1999). Second, it may also help to control for differences in measurement error between individual animals because data for each individual are fitted to their own curve. However, the central assumption of the method (i.e., that normothermic $T_{\mathrm{b}}$ necessarily fits a normal distribution for a small-bodied heterothermic endotherm) may not always apply because of factors that can influence $T_{\mathrm{b}}$ within the normothermic range. To begin with, as a result of circadian $T_{\mathrm{b}}$ variation, normothermic $T_{\mathrm{b}}$ measurements may often be better described using bimodal rather than unimodal patterns (e.g., Aujard and Vasseur 2001; Warnecke et al. 2007), which may complicate assumptions about the symmetry of distributions. Responses to $T_{\mathrm{a}}$ variation could also play a role. For example, if it tends to be cool during the study, an animal may spend most of that time at a lower normothermic $T_{b}$, but measurements obtained on a few hot days, during which $T_{\mathrm{b}}$ is regulated at higher levels, will skew the distribution (Refinetti 1997; Aujard and Vasseur 2001). Measurements of $T_{\text {sk }}$ may be especially sensitive to these kinds of effects because of the potential influence of $T_{a}$ on external temperaturesensitive radiotransmitters (Barclay et al. 1996; Audet and 
Thomas 1996; Willis and Brigham 2003; McKechnie et al. 2007). Even differences in foraging success on different days could influence the shape of the distribution because the heat increment of feeding can affect $T_{\mathrm{b}}$ variation within the normothermic range (e.g., Campbell et al. 2000). If a normothermic animal typically thermoregulates about some modal value, a small number of particularly successful (or unsuccessful) foraging bouts during the measurement period could also skew the distribution. Given these potential sources of error, it is important to validate the central assumption of the normal-distribution method.

The eventual goal for field studies of torpor is to quantify the energetic and, by extension, fitness consequences of heterothermy for free-living endotherms. Therefore, a threshold temperature that reflects energy savings due to torpor should have the greatest relevance to energy balance and fitness. To address the issue of defining torpor bouts for field and laboratory studies where it is not possible to measure MR, here I present a new approach for quantifying a threshold temperature. My objective was to quantify the effect of the independent variables $\mathrm{BM}$ and $T_{\mathrm{a}}$ on the dependent variable $T_{\mathrm{b}}$ at the immediate onset of torpor bouts (hereafter $T_{\mathrm{b} \text {-onset }}$ ) for mammals. Body size and $T_{\mathrm{a}}$ influence most physiological traits of endotherms, including thermal conductance, the rate of heat exchange with the environment. Small animals have higher rates of heat loss than large animals, and this effect is more pronounced at lower values of $T_{\mathrm{a}}$ (Withers 1992; Geiser 2004). This will influence measurements of $T_{\mathrm{b}}$ at the start of a torpor bout and must be incorporated into a $T_{\mathrm{b}}$-based threshold for torpor. I predicted that $T_{\mathrm{b} \text {-onset }}$ would scale positively with BM and that this effect would be most pronounced at low values of $T_{\mathrm{a}}$ because higher rates of heat loss for small species should result in a more rapid initial decline of $T_{\mathrm{b}}$ immediately after thermoregulation of the normothermic set point is abandoned. I also compared values of threshold temperatures calculated using McKechnie et al.'s (2007) normaldistribution method with values of $T_{\mathrm{b} \text {-onset }}$ that I determined for the same species.

\section{Material and Methods}

I obtained data on $T_{\text {b-onset }}$ from 18 studies of 14 species of mammals ranging in size from 14.7 to $406.0 \mathrm{~g}$ (Table 1). Ambient temperature ranged from $2.5^{\circ}$ to $28.4^{\circ} \mathrm{C}$ at the time of torpor onset during experimental runs (Table 1). Data were obtained from figures depicting simultaneous traces of $T_{\mathrm{b}}$ and oxygen consumption during bouts of normothermy and torpor. I digitized each figure using TechDig, version 2.0 (Jones 1998), and identified the point on each time course when MR first declined abruptly from the resting normothermic level at the start of a torpor bout (Fig. 1). In all studies, the time of torpor entry was clear from a distinct and rapid reduction in MR. I selected $T_{\mathrm{b}-\text { onset }}$ for each figure as the $T_{\mathrm{b}}$ recorded at the same time as the initial reduction in MR. In most studies, $T_{\mathrm{a}}$ was reported in the text or figure caption, but in a few, it was depicted as a separate trace in the time course figure. In these latter instances I also used TechDig to identify $T_{\mathrm{a}}$ at the time of torpor entry. In all studies, $T_{\mathrm{a}}$ was stable within $4^{\circ} \mathrm{C}$ for at least $30 \mathrm{~min}$ before and after entry into torpor. I was able to obtain multiple values of $T_{\mathrm{b} \text {-onset }}$ over a range of $T_{\mathrm{a}}$ and $\mathrm{BM}$ values for nine species (two to four values per species) either because time courses for multiple individuals were presented in one study or because more than one study was published for an individual species.

Although there was clear agreement between $T_{\mathrm{b}}$ and MR traces from all studies in terms of timing of torpor entry (e.g., Fig. 1), there was the potential that washout characteristics of respirometry systems used in the original studies had affected my results. For example, a low flow rate would extend the washout time and could delay detection of the MR decline at torpor onset (Lasiewski et al. 1966; Bartholomew et al. 1981). Fifteen studies provided information on chamber volume and flow rate, which allowed me to estimate the washout time needed to reach $99 \%$ equilibrium in the metabolic chamber. I used the equation

$$
\text { washout time }=4.6\left(\frac{V}{\mathrm{FR}}\right) \text {, }
$$

where $V$ equals chamber volume and FR equals flow rate (Lasiewski et al. 1966). To rule out the influence of washout on my findings, I tested for correlations between washout estimates and both independent variables, as well as values of $T_{\mathrm{b} \text {-onset }}$.

In addition to potential washout effects, I tested for an effect of mammalian subclass on $T_{\mathrm{b} \text {-onset }}$ before analyzing the pooled data set because normothermic $T_{\mathrm{b}}$ of marsupial mammals is known to be lower than that of placentals (Withers 1992). To evaluate whether $T_{\mathrm{b} \text {-onset }}$ represents a realistic threshold for torpor, I also compared values of $T_{\mathrm{b}-\text { onset }}$ to normothermic $T_{\mathrm{b}}$ values reported by Geiser (2004) and to average normothermic values I determined from $T_{\mathrm{b}}$ time courses in each of the studies I analyzed (see below).

I calculated torpor threshold temperatures using McKechnie et al.'s (2007) normal-distribution method. I used TechDig to sample between five and 12 representative values (mean \pm $\mathrm{SD}=9.9 \pm 2.3$ samples) of normothermic $T_{\mathrm{b}}$ from each of the time course figures. Values were sampled at times when animals were clearly normothermic based on their corresponding MR trace. I sampled at equivalent time intervals for each time course (e.g., every $0.5 \mathrm{~h}$ ), but the sampling interval varied from 0.5 to $2.5 \mathrm{~h}$ for different time courses, depending on the duration of normothermic recordings. I selected sampling intervals such that values spanned the entire duration of each time course. I also sampled the maximum $T_{\mathrm{b}}$ recorded during each run. For 
Table 1: Data for body mass $(\mathrm{BM})$, ambient temperature $\left(T_{\mathrm{a}}\right)$, and body temperature at the time of torpor onset $\left(T_{\mathrm{b}-\text { onset }}\right)$ obtained from the literature, as well as values of $T_{\mathrm{b} \text {-onset }}-1 \mathrm{SE}$ calculated for each species with equation (4)

\begin{tabular}{|c|c|c|c|c|c|c|}
\hline Species & BM (g) & $T_{\mathrm{a}}\left({ }^{\circ} \mathrm{C}\right)$ & $\begin{array}{l}T_{\text {b-onset }} \\
\left({ }^{\circ} \mathrm{C}\right)\end{array}$ & $\begin{array}{l}T_{\text {b-onset }}-1 \mathrm{SE} \\
\left({ }^{\circ} \mathrm{C}\right)\end{array}$ & $T_{\text {b-norm }}\left({ }^{\circ} \mathrm{C}\right)$ & Reference \\
\hline \multicolumn{7}{|l|}{ Eutheria: } \\
\hline \multirow{4}{*}{ Elephantulus rozeti } & 49.2 & 20.0 & 36.3 & 33.9 & $37.3 \pm .31$ & Lovegrove et al. 2001 \\
\hline & 49.2 & 15.0 & 36.5 & 33.7 & $37.2 \pm .57$ & Lovegrove et al. 2001 \\
\hline & 49.2 & 10.0 & 36.0 & 33.5 & $36.8 \pm 1.07$ & Lovegrove et al. 2001 \\
\hline & 49.2 & 5.0 & 36.9 & 33.3 & $37.5 \pm .56$ & Lovegrove et al. 2001 \\
\hline Eptesicus fuscus & 14.7 & 2.5 & 32.9 & 31.8 & $36.5 \pm .79$ & Willis et al. $2005 b$ \\
\hline \multirow[t]{3}{*}{ Glis glis } & 140.0 & 12.8 & 36.4 & $\ldots$ & $36.0 \pm .57$ & Wilz and Heldmaier 2000 \\
\hline & 140.0 & 5.1 & 34.9 & $\ldots$ & $33.7 \pm .61$ & Wilz and Heldmaier 2000 \\
\hline & 140.0 & 15.0 & 35.3 & $\ldots$ & $35.3 \pm .58$ & Wilz and Heldmaier 2000 \\
\hline \multirow[t]{3}{*}{ Macroglossus minimus } & 15.5 & 15.0 & 34.2 & 32.3 & $35.7 \pm .69$ & Bartels et al.1998 \\
\hline & 15.5 & 20.0 & 34.3 & 32.5 & $36.6 \pm .96$ & Bartels et al.1998 \\
\hline & 15.5 & 24.0 & 35.0 & 32.7 & $37.3 \pm .79$ & Bartels et al.1998 \\
\hline \multirow[t]{3}{*}{ Microcebus murinus } & 62.0 & 9.8 & 36.0 & 34.0 & $35.5 \pm 1.65$ & Schmid 1996 \\
\hline & 59.0 & 22.8 & 34.9 & 34.4 & $36.5 \pm .96$ & Schmid 2000 \\
\hline & 52.5 & 16.2 & 35.4 & 33.9 & $36.4 \pm 1.21$ & Schmid 2000 \\
\hline \multirow[t]{3}{*}{ Microcebus myoxinus } & 37.0 & 11.8 & 33.2 & 33.1 & $33.9 \pm 1.68$ & Schmid 1996 \\
\hline & 29.0 & 14.7 & 33.4 & 32.9 & $34.1 \pm 1.97$ & Schmid 1996 \\
\hline & 30.0 & 12.9 & 35.6 & 32.8 & $35.6 \pm .91$ & Schmid et al. 2000 \\
\hline Perognathus hispidus & 40.1 & 11.0 & 34.9 & 33.2 & 35.2 & Wang and Hudson 1970 \\
\hline Peromyscus eremicus & 15.0 & 19.5 & 33.2 & 32.5 & $37.0 \pm 1.58$ & MacMillen 1965 \\
\hline Phodopus sungorus & 25.0 & 10.0 & 32.7 & 32.5 & $36.2 \pm 1.03$ & Heldmaier and Ruf 1992 \\
\hline Spermophilus lateralis & 280.0 & 4.0 & 35.1 & $\ldots$ & 37.0 & Steiger 1992 \\
\hline \multirow[t]{2}{*}{ Spermophilus richardsonii } & 406.0 & 15.0 & 35.0 & $\ldots$ & 37.1 & Wang 1978 \\
\hline & 406.0 & 5.0 & 34.9 & $\ldots$ & 37.1 & Wang 1978 \\
\hline \multirow[t]{2}{*}{ Syconycteris australis } & 18.0 & 18.0 & 35.3 & 32.5 & $35.8 \pm .85$ & Coburn and Geiser 1998 \\
\hline & 18.0 & 11.1 & 33.2 & 32.3 & $34.6 \pm .60$ & Geiser et al. $1996 a$ \\
\hline \multicolumn{7}{|l|}{ Marsupialia: } \\
\hline \multirow[t]{4}{*}{ Cercartetus nanus } & 36.2 & 19.8 & 34.5 & 33.4 & $35.0 \pm 1.23$ & Song et al. $1998 b$ \\
\hline & 36.2 & 28.4 & 36.8 & 33.7 & $35.8 \pm 1.28$ & Song et al. $1998 b$ \\
\hline & 36.7 & 12.0 & 33.9 & 33.1 & $34.3 \pm .55$ & Westman and Geiser 2004 \\
\hline & 36.7 & 20.0 & 35.9 & 33.4 & $34.5 \pm 1.23$ & Westman and Geiser 2004 \\
\hline \multirow[t]{3}{*}{ Sminthopsis macroura } & 24.7 & 19.0 & 33.5 & 32.9 & $35.6 \pm 1.57$ & Geiser et al. $1996 b$ \\
\hline & 22.5 & 18.0 & 34.0 & 32.7 & $34.2 \pm 1.73$ & Song and Geiser 1997 \\
\hline & 22.5 & 28.0 & 35.9 & 33.1 & $35.5 \pm 1.22$ & Song and Geiser 1997 \\
\hline
\end{tabular}

Note. Data for normothermic $T_{\mathrm{b}}\left(T_{\mathrm{b}-\mathrm{norm}}\right)$ are mean $\pm \mathrm{SD}$ of values sampled from $T_{\mathrm{b}}$ time courses, except for those from P. hispidus, S. lateralis, and S. richardsonii, which are from Geiser (2004).

each set of $T_{\mathrm{b}}$ values, I calculated the average $T_{\mathrm{b}}$ and fitted a normal distribution, assuming that the maximum recorded value represented the upper 99\% confidence limit (CL; McKechnie et al. 2007). By definition, a normal distribution is symmetrical about the mean (Zar 1999), so if the upper $99 \%$ CL is known (or assumed), the lower limit can be calculated by simple subtraction using the equation

$$
\text { lower } \mathrm{CL}=\text { mean }-(\text { upper } \mathrm{CL}-\text { mean }) \text {. }
$$

I defined this lower limit as the torpor threshold after
McKechnie et al. (2007). For each distribution, I tested for skewness and concluded significance if skewness values divided by the standard error of skewness were greater than 2 (Zar 1999). I also compared torpor threshold values calculated using equation (2) with values of $T_{\mathrm{b} \text {-onset }}$ that $\mathrm{I}$ determined for the same species. I restricted this comparison to species with body mass smaller than $70 \mathrm{~g}$ because of my results for $T_{\text {b-onset }}$ (see below).

I used Systat, version 11 (Systat Software, San Jose, CA), for all statistical analyses. I log transformed nonnormal data where necessary and used an $\alpha$ level of 0.05 to assess signif- 


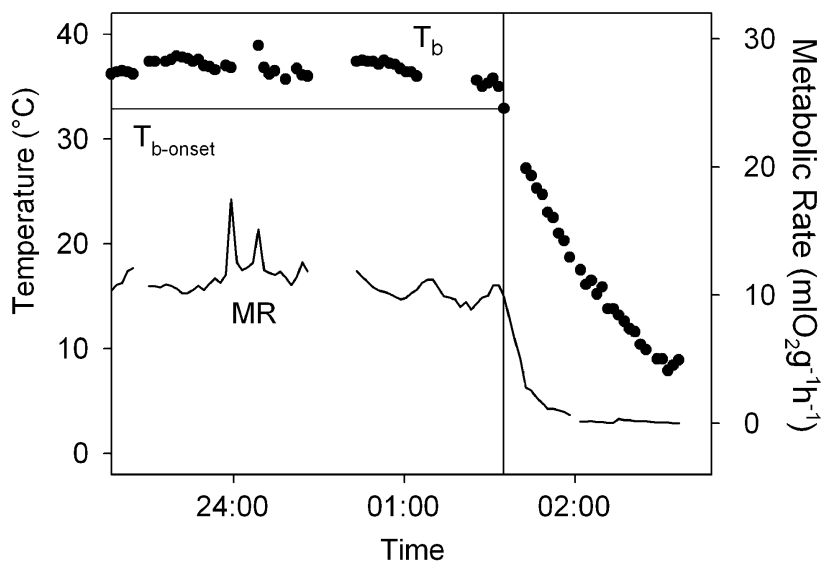

Figure 1. Typical time course plot showing representative traces of $T_{\mathrm{b}}$ and metabolic rate (MR) from which I obtained values of $T_{\text {b-onset. }}$ The vertical line corresponds to a clear decline in MR from the resting normothermic level. I defined the $T_{\mathrm{b}}$ measured at this time as $T_{\mathrm{b}-\text { onset }}$. Data replotted from Willis et al. (2005b) for Eptesicus fuscus.

icance. Values reported are the mean \pm SD unless stated otherwise.

\section{Results}

There was no correlation between washout estimates for respirometry chambers used in the original studies and $T_{\mathrm{a}}, \mathrm{BM}$, or values of $T_{\text {b-onset }}$ (Pearson $r<0.20$ ), which suggests that washout did not influence my results. When I controlled for BM and $T_{\mathrm{a}}$, there was no effect of subclass on $T_{\mathrm{b}-\text { onset }}$ (ANCOVA: $\left.F_{28,1}=0.44, P=0.52\right)$, so I pooled the data from all species in subsequent analyses. A general linear model (GLM) relating the independent variables, $T_{\mathrm{a}}$ and the base- 10 logarithm of BM, with the dependent variable, $T_{\mathrm{b} \text {-onset }}$, for all mammals was significant $\left(F_{2,28}=5.28, P=0.01, r^{2}=0.27\right)$. However, there was a clear plateau in the relationship between $\mathrm{BM}$ and $T_{\mathrm{b} \text {-onset }}$ for values of body mass between 70 and $140 \mathrm{~g}$ (Fig. 2A). Therefore, I repeated the analysis excluding mammals heavier than $70 \mathrm{~g}$, using nontransformed BM. This left only 11 species (range of body mass $=14.7-62.0 \mathrm{~g}$ ) but dramatically improved the explanatory power of the model (Fig. $2 B ; F_{2,23}=9.9, P=$ $\left.0.001, r^{2}=0.46\right)$. Effects of BM $(t=3.9, P<0.001)$ and $T_{\mathrm{a}}$ $(t=2.26, P=0.03)$ both contributed significantly, and the linear model was described by the equation

$$
\begin{aligned}
T_{\mathrm{b}-\text { onset }}= & (0.055 \pm 0.014) \mathrm{BM}+(0.071 \pm 0.031) \mathrm{T}_{\mathrm{a}} \\
& +(31.823 \pm 0.740),
\end{aligned}
$$

where values represent parameter estimates \pm 1 SE (Table 2). Standard error values in this equation reflect the precision of model parameter estimates. A conservative approach, then, which accounts for error associated with the precision of pa- rameter estimation and avoids overestimating use of torpor, would be to use $T_{\mathrm{b}-\text { onset }}-1 \mathrm{SE}$ to calculate the threshold $T_{\mathrm{b}}$ (Tables 1, 2; Fig. 3). Subtracting SE for each parameter estimate modifies equation ( 3 ) to

$$
T_{\text {b-onset }}-1 \mathrm{SE}=(0.041) \mathrm{BM}+(0.040) \mathrm{T}_{\mathrm{a}}+31.083 .
$$

Values of $T_{\text {b-onset }}$ used to generate these equations were slightly but significantly lower than values of normothermic $T_{\mathrm{b}}$ reported by Geiser (2004) for the same species $\left(34.8^{\circ} \pm 1.3^{\circ}\right.$ vs. $36.0^{\circ} \pm 1.4^{\circ} \mathrm{C}$; paired $t$-test: $\left.t=3.9, \mathrm{df}=25, P=0.001\right)$ as well as average normothermic values obtained from the $T_{\mathrm{b}}$
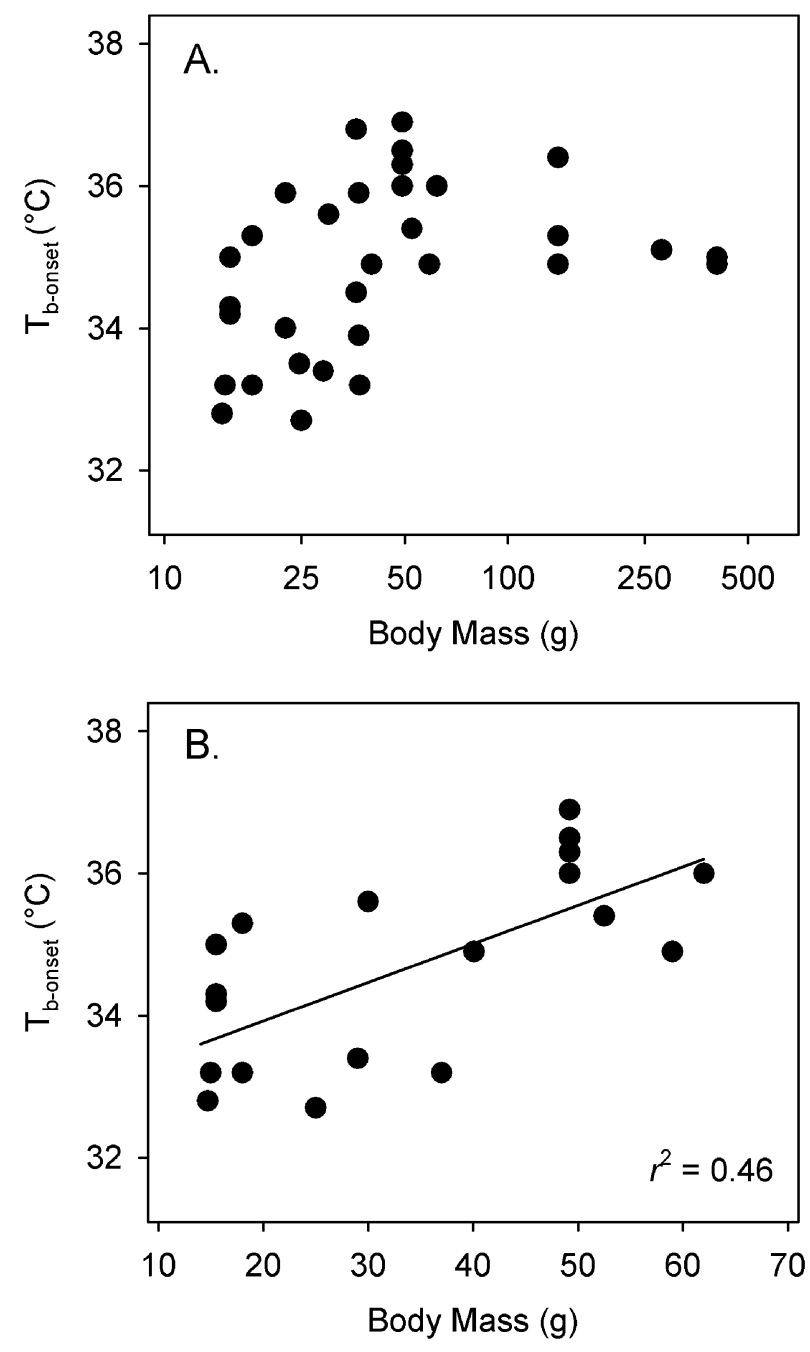

Figure 2. Plots of body mass (BM) versus $T_{\mathrm{b}-\text { onset }}$ for all mammals for which data are available $(A)$ and for mammals lighter than $70 \mathrm{~g}(B)$. Note that body mass in $A$ is plotted on a log scale. See text (eq. [3]) for general linear model results. The solid line in $B$ represents predicted values of $T_{\mathrm{b} \text {-onset }}$ for body masses smaller than $70 \mathrm{~g}$, calculated using equation (3) and assuming $T_{\mathrm{a}}=14^{\circ} \mathrm{C}$, the mean $T_{\mathrm{a}}$ to which animals were exposed in the original studies. 
Table 2: Sample values for $T_{\mathrm{b} \text {-onset }}$ predicted by equation (3) and $T_{\mathrm{b}-\text { onset }}-1 \mathrm{SE}$ predicted by equation

(4) for mammals of body mass 5-40 $\mathrm{g}$ at three different values of $T_{\mathrm{a}}$

\begin{tabular}{ccc}
\hline $\begin{array}{c}T_{\mathrm{a}} \text { and } \\
\mathrm{BM}(\mathrm{g})\end{array}$ & $\begin{array}{l}T_{\text {b-onset }}\left({ }^{\circ} \mathrm{C}\right) \\
5.0^{\circ} \mathrm{C}:\end{array}$ & $\begin{array}{l}T_{\text {b-onset }}-1 \mathrm{SE} \\
\left({ }^{\circ} \mathrm{C}\right)\end{array}$ \\
5.0 & 32.5 & 31.5 \\
10.0 & 32.7 & 31.7 \\
20.0 & 33.3 & 32.1 \\
30.0 & 33.8 & 32.5 \\
40.0 & 34.4 & 32.9 \\
$10.0^{\circ} \mathrm{C}:$ & & \\
5.0 & 32.8 & 31.7 \\
10.0 & 33.1 & 31.9 \\
20.0 & 33.6 & 32.3 \\
30.0 & 34.2 & 32.7 \\
40.0 & 34.7 & 33.1 \\
$20.0^{\circ} \mathrm{C}:$ & & \\
5.0 & 33.5 & 32.1 \\
10.0 & 33.8 & 32.3 \\
20.0 & 34.3 & 32.7 \\
30.0 & 34.9 & 33.1 \\
40.0 & 35.4 & 33.5 \\
\hline
\end{tabular}

Note. $T_{\mathrm{b}-\text { onset }}-1 \mathrm{SE}$ represents a conservative threshold between torpor and normothermia for field studies of small mammals.

traces in the studies I analyzed $\left(35.8^{\circ} \pm 1.1^{\circ} \mathrm{C}\right.$; Table 1 ; paired $t$-test: $t=4.1, \mathrm{df}=31, P<0.001)$. This suggests that $T_{\mathrm{b} \text {-onset }}$ represents a realistic threshold between torpor and normothermia.

None of the distributions of normothermic $T_{\mathrm{b}}$ that I obtained from the original studies were significantly skewed. There was a weak but significant linear relationship between values of $T_{\mathrm{b} \text {-onset }}$ and torpor threshold values calculated for the same respirometry trials using the normal-distribution method $\left(F_{1,24}=7.56, P=\right.$ $\left.0.01, r^{2}=0.24\right)$. I used a paired $t$-test to control for differences in $T_{\mathrm{a}}$ and $\mathrm{BM}$ between trials and found that values of $T_{\mathrm{b} \text {-onset }}$ obtained from the original studies $\left(34.8^{\circ} \pm 1.3^{\circ} \mathrm{C}\right)$ were slightly but significantly higher than values calculated by the normaldistribution method $\left(34.1^{\circ} \pm 1.6^{\circ} \mathrm{C}\right.$; paired $t$-test: $t=2.3$, $\mathrm{df}=25, P=0.03)$. However, values of $T_{\mathrm{b}-\text { onset }}-1 \mathrm{SE}$ calculated based on $\mathrm{BM}$ and $T_{\mathrm{a}}$ by equation $(4)\left(33.1^{\circ} \pm 0.6^{\circ} \mathrm{C}\right)$ were significantly lower than those calculated using the normal-distribution method (Table 1; paired $t$-test: $t=3.3$, df $=25, P=$ $0.003)$.

\section{Discussion}

Oxygen consumption, as a proxy for $\mathrm{MR}$, is a far better variable to measure than $T_{\mathrm{b}}$ for determining when endotherms begin to save energy as a result of heterothermy, but for many studies, especially in the field, we are limited to measurement of some less precise correlate of MR. A few studies of small endotherms have employed heart rate telemetry as a metabolic proxy, and heart rate has potential for future studies of torpor in small mammals (Butler et al. 2004; Cooke et al. 2004; Bowlin et al. 2005). However, the vast majority of field and enclosure studies of torpor employ measurements of $T_{\mathrm{b}}$ or $T_{\mathrm{sk}}$. Thus, it is necessary to quantify $T_{\mathrm{b}}$ - or $T_{\mathrm{sk}}$-based boundaries between torpor and normothermia as objectively as possible. Over some timescale, every animal must achieve a balance between energy acquisition and consumption to survive and reproduce, so energy is fundamental to reproductive fitness and is the currency we must address to understand use of torpor in the wild. Values of $T_{\text {b-onset }}$ calculated by the models presented here (eqq. [3], [4]; Table 2) have a stronger physiological justification than thresholds for torpor based on arbitrary values of $T_{b}, T_{b}-T_{a}$ differentials, behavioral activity, or frequency distributions of $T_{\mathrm{b}}$ measurements because they reflect the onset of energy savings that result from abandoning regulation of the normothermic $T_{\mathrm{b}}$ set point at the start of a torpor bout. This said, only a small number of studies have presented the data required to determine $T_{\mathrm{b} \text {-onset }}$, so the sample size for my analysis was small. More data are needed to validate the models, but until they are available, $T_{\mathrm{b} \text {-onset }}$ may be useful for defining torpor bouts when MR cannot be measured. To be conservative and account for error associated with the precision of model parameter estimates, I recommend using values of $T_{\mathrm{b} \text {-onset }}-1 \mathrm{SE}$, calculated by equation (4).

For mammals heavier than a certain threshold (between 62 and $140 \mathrm{~g}$ ), my findings tentatively justify use of a single value

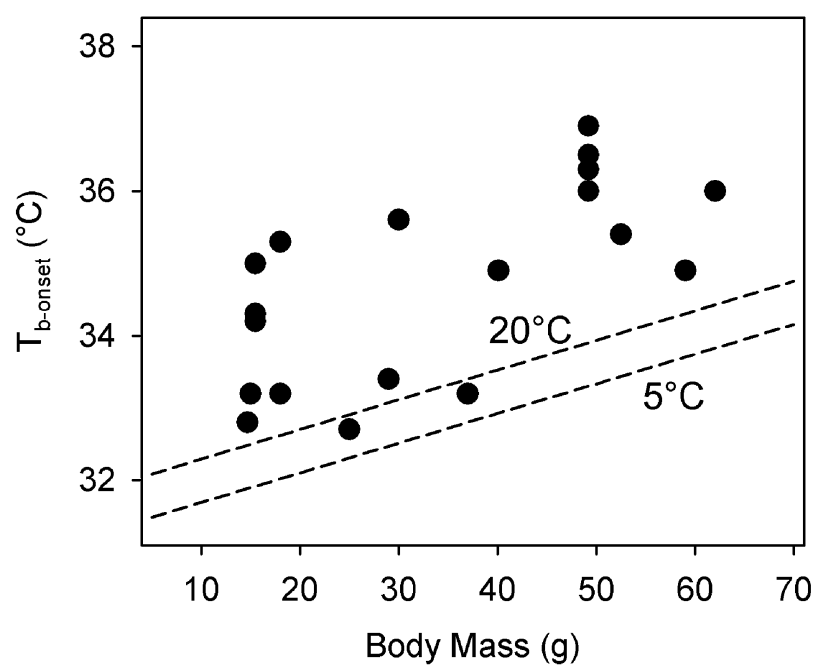

Figure 3. Data from Figure $2 B$, replotted with lines representing $T_{\mathrm{b}-\text { onset }}-1 \mathrm{SE}$ calculated from equation (4), assuming $T_{\mathrm{a}}=5^{\circ} \mathrm{C}$ (lower line) and $20^{\circ} \mathrm{C}$ (upper line). 
of $T_{\mathrm{b}}$ to differentiate torpor from normothermia because there was an obvious plateau in $T_{\text {b-onset }}$ above this threshold (Fig. 1A). The mean value of $T_{\mathrm{b} \text {-onset }}$ for mammals $>62 \mathrm{~g}$ was $35.3^{\circ} \pm$ $0.4^{\circ} \mathrm{C}$, much higher than the $30^{\circ} \mathrm{C}$ cutoff used in most studies (Barclay et al. 2001). A plateau in $T_{\text {b-onset }}$ above a threshold BM is not surprising. Large endotherms have high thermal inertia and will cool slowly at the immediate onset of torpor (Geiser 2004). This also explains the strong relationship between $T_{\mathrm{b}}$ onset and BM for mammals lighter than $62 \mathrm{~g}$. However, normothermic $T_{\mathrm{b}}$ of mammals obviously has an upper limit, so the positive relationship between $\mathrm{BM}$ and $T_{\mathrm{b} \text {-onset }}$ can extend only so far. There was a large gap in my data set between $\mathrm{BM}=62$ and $140 \mathrm{~g}$, so more data are needed to determine the BM at which this plateau actually occurs. The gap reflects, in part, the fact that most heterothermic mammals are smaller than this but also that few studies of torpor in mammals $>62$ $\mathrm{g}$ have presented concurrent traces of $\mathrm{MR}$ and $T_{\mathrm{b}}$. In any case, small mammals below this threshold BM are the most likely to be heterothermic (Geiser 2004), so the relationship between $T_{\mathrm{b}-\text { onset }}$ and BM should apply to the majority of heterothermic species. For large species, McKechnie et al.'s (2007) normaldistribution approach may work well if it can be confirmed that normothermic $T_{\mathrm{b}}$ fits a normal distribution for free-ranging individuals of the species under study.

A significant proportion (46\%) of variation in $T_{\mathrm{b} \text {-onset }}$ was explained by BM and $T_{\mathrm{a}}$, but there was considerable residual variation, which could be influenced by a number of factors, including phylogenetic effects. I was surprised not to detect an effect of subclass on $T_{b \text {-onset. }}$. Given the difference in normothermic $T_{\mathrm{b}}$ between marsupial and placental mammals (Withers 1992), taxon-specific effects are likely to influence the true threshold differentiating torpor and normothermia. The fact that I did not detect this difference may reflect the small sample of $T_{\text {b-onset }}$ data available, especially for marsupials. Taxon-specific effects at levels below subclass could also influence normothermic $T_{\mathrm{b}}$ and cooling rates, so, ideally, to control for phylogenetic effects, analyses of $T_{\mathrm{b} \text {-onset }}$ should be conducted within species. Future studies should undertake trials recording MR during torpor entry over a range of $T_{\mathrm{a}}$ for conspecifics that vary in BM. By controlling for phylogenetic influence, speciesspecific equations for $T_{\mathrm{b} \text {-onset }}$ are likely to provide more accurate threshold $T_{\mathrm{b}}$ 's than those calculated by equation (4).

My results provide tentative support for McKechnie et al.'s (2007) normal-distribution method as another means for defining the torpor threshold. None of the normothermic $T_{\mathrm{b}}$ frequency distributions I analyzed were significantly skewed, so the central assumption of the method was valid for the subset of mammals I studied. I also found a significant correlation between values of $T_{\mathrm{b} \text {-onset }}$ and $T_{\mathrm{b}}$ values calculated by the normaldistribution approach, and differences between values predicted by the two methods, while significant, were small (about $1^{\circ} \mathrm{C}$ ). These findings indicate that, again, for this subset of mammals, the two methods provide comparable results. However, support for the normal-distribution approach remains equivocal because I was able to analyze only very small numbers of normothermic $T_{\mathrm{b}}$ data points for each respirometry run. Data sets from free-living animals are certain to be many times larger. Furthermore, most animals included in my analysis were postabsorptive and measured in the laboratory, so, relative to a field setting, there would have been much less variation in factors that could affect the symmetry of $T_{\mathrm{b}}$ distributions. In any case, within-species analyses of effects of $T_{\mathrm{a}}$ and $\mathrm{BM}$ on $T_{\mathrm{b} \text {-onset }}$ are likely to provide estimates of the torpor threshold that are more relevant to energy balance and reproductive fitness than either equation (4) or the normal-distribution method. These analyses would control for phylogenetic effects while providing threshold $T_{\mathrm{b}}$ 's that account for physiological attributes of the animals themselves (i.e., heat loss under different conditions and the onset of energy savings during torpor) rather than statistical properties of measurements.

For a large number of species, the use of implanted devices to measure $T_{\mathrm{b}}$ is impractical if not impossible in the field. For example, many insect-eating bats are small bodied but have very large home ranges. This means that surgically implanted radiotransmitters are not useful because of their small range of signal detection (Barclay et al. 2001; Willis and Cooper, forthcoming). For threatened species or populations, surgical procedures for transmitter implantation may pose too great a risk. In these cases, $T_{\mathrm{sk}}$ must be measured as a proxy for $T_{\mathrm{b}}$ and can yield valuable data if its limitations are taken into account (Barclay et al. 1996; Audet and Thomas 1996; Willis and Brigham 2003; Dausmann et al. 2005). Measurements of $T_{\text {sk }}$ may be affected by both $T_{\mathrm{a}}$ and BM because of the influence of both variables on thermal conductance. In terms of the torpor threshold, effects of $T_{\mathrm{a}}$ in particular will probably be larger for values of $T_{\text {sk-onset }}$ than for those of $T_{\mathrm{b} \text {-onset. }}$ External transmitters are subject to ambient heating and cooling, which can result in $T_{\mathrm{b}}-T_{\mathrm{sk}}$ differentials of $6^{\circ} \mathrm{C}$ or more during steady state normothermia, and the magnitude of these differentials is influenced by $T_{\mathrm{a}}$ (Barclay et al. 1996; Audet and Thomas 1996; Willis and Brigham 2003; McKechnie et al. 2007). To my knowledge there are no published time course data depicting concurrent traces of $T_{\text {sk }}$ and MR from which values for $T_{\text {sk-onset }}$ could be determined. These data are needed to quantify an energy-relevant $T_{\mathrm{sk}}$ threshold for torpor to be used in field studies of small, free-ranging mammals.

\section{Acknowledgments}

I thank members of the Bat and Bird Lab at the University of Regina, Canada, and members of the Centre for Behavioural and Physiological Ecology at the University of New England, Australia, for discussion that prompted this work. Mark Brigham, Paul Cryan, Fritz Geiser, Chris Pavey, and Chris Turbill provided helpful suggestions that improved the manuscript, 
and discussions with Robert Barclay were also very useful. I also thank two anonymous reviewers for insightful comments and am particularly grateful to one of them for pointing me toward the normal-distribution method.

\section{Literature Cited}

Audet D. and D.W. Thomas. 1996. Evaluation of the accuracy of body temperature measurement using external radio transmitters. Can I Zool 74:1778-1781.

Augee M.L. 1969. Temperature Regulation and Adrenal Function in the Echidna. PhD diss. Monash University, Clayton.

Aujard F. and F. Vasseur. 2001. Effect of ambient temperature on the body temperature rhythm of male gray mouse lemurs (Microcebus murinus). Int I Primatol 22:43-56.

Austin G.T. and W.G. Bradley. 1969. Additional responses of the poor-will to low temperature. Auk 86:717-725.

Barclay R.M.R., M.C. Kalcounis, L.H. Crampton, C. Stefan, M.J. Vonhof, L. Wilkinson, and R.M. Brigham. 1996. Can external radiotransmitters be used to assess body temperature and torpor in bats? L Mammal 77:1102-1106.

Barclay R.M.R., C.L. Lausen, and L. Hollis. 2001. What's hot and what's not: defining torpor in free-ranging birds and mammals. Can J Zool 79:1885-1890.

Bartels W., B.S. Law, and F. Geiser. 1998. Daily torpor and energetics in a tropical mammal, the northern blossom-bat Macroglossus minimus (Megachiroptera). L Comp Physiol B 168:233-239.

Bartholomew G.A., D. Vleck, and C.M. Vleck. 1981. Instantaneous measurement of oxygen consumption during preflight warm-up and post-flight cooling in sphingid and saturniid moths. J Exp Biol 90:17-32.

Bligh J. and K.G. Johnson. 1973. Glossary of terms for thermal physiology. LAppl Physiol 35:941-961.

Bowlin M.S., W.W. Cochran, and M.C. Wikelski. 2005. Biotelemetry of New World thrushes during migration: physiology, energetics and orientation. Integr Comp Biol 45:295404.

Bradley W.G. and M.J. O'Farrell. 1969. Temperature relationships in the western pipistrelle (Pipistrellus hesperus). Pp. 8596 in C.C. Hoff and M.L. Riedesel, eds. Physiological Systems in Semi-arid Environments. University of New Mexico Press, Albuquerque.

Butler P.J., J.A. Green, I.L. Boyd, and J.R. Speakman. 2004. Measuring metabolic rate in the field: the pros and cons of the doubly labelled water and heart rate methods. Funct Ecol 18:168-183.

Campbell K.L., I.W. McIntyre, and R.A. MacArthur. 2000. Postprandial heat increment does not substitute for active thermogenesis in cold-challenged star-nosed moles (Condylura cristata). L Exp Biol 203:301-310.

Coburn D.K. and F. Geiser. 1998. Seasonal changes in energetics and torpor patterns in the subtropical blossom-bat Syconycteris australis (Megachiroptera). Oecologia 113:467-473.

Cooke S.J., S.G. Hinch, M. Wikelski, R.D. Andrews, L.J. Kuchel, T.G. Wolcott, and P.J. Butler. 2004. Biotelemetry: a mechanistic approach. Trends Ecol Evol 19:334-343.

Cooper C.E. and P.C. Withers. 2004. Patterns of body temperature variation and torpor in the numbat, Myrmecobius fasciatus (Marsupialia: Myrmecobiidae). I Therm Biol 29: 277-284.

Dausmann K.H., J. Glos, J.U. Ganzhorn, and G. Heldmaier. 2005. Hibernation in the tropics: lessons from a primate. I Comp Phvsiol B 175:147-155.

Dietz M. and E.K.V. Kalko. 2005. Seasonal changes in daily torpor patterns of free-ranging female and male Daubenton's bats (Myotis daubentonii). L Comp Physiol B 175:1-9.

Geiser F. 2004. Metabolic rate and body temperature reduction during hibernation and daily torpor. Annu Rev Physiol 66: 239-274.

Geiser F., D.K. Coburn, G. Körtner, and B.S. Law. 1996a. Thermoregulation, energy metabolism, and torpor in blossom bats, Syconycteris australis (Megachiroptera). L Zool (Lond) 239:583-590.

Geiser F., X. Song, and G. Körtner. 1996b. The effect of $\mathrm{He}-\mathrm{O}_{2}$ exposure on metabolic rate, thermoregulation and thermal conductance during normothermia and daily torpor. L Comp Phvsiol B 166:190-196.

Heldmaier G. and T. Ruf. 1992. Body temperature and metabolic rate during natural hypothermia in endotherms. I Comp Physiol B 162:696-706.

Hirshfeld J.R. and M.J. O'Farrell. 1976. Comparisons of differential warming rates and tissue temperatures in some species of desert bats. Comp Biochem Phvsiol A 55:83-87.

IUPS Thermal Commission. 2003. Glossary of terms for thermal physiology. 3rd ed. L Therm Biol 28:75-106.

Jones R.B. 1998. TechDig, version 2.0. Distributed by the author, Mundelein, IL.

Körtner G. and F. Geiser. 2000. Torpor and activity patterns in free-ranging sugar gliders Petaurus breviceps (Marsupialia). Oecologia 123:350-357.

Lasiewski R.C., A.L. Acosta, and M.H. Bernstein. 1966. Evaporative water loss in birds. 1. Characteristics of the open flow method of determination, and their relation to estimates of thermoregulatory ability. Comp Biochem Phvsiol 19:445457.

Lausen C.L. and R.M.R. Barclay. 2003. Thermoregulation and roost selection by reproductive female big brown bats (Eptesicus fuscus) roosting in rock crevices. L Zool (Lond) 260: 235-244.

Lovegrove B.G., J. Raman, and M.R. Perrin. 2001. Heterothermy in elephant shrews, Elephantulus spp. (Macroscelidea): daily torpor or hibernation? I Comp Physiol B 171:1-10.

MacMillen R.E. 1965. Aestivation in the cactus mouse, Peromyscus eremicus. Comp Biochem Physiol 16:227-248. 
McKechnie A.E., R.A.M. Ashdown, M.B. Christian, and R.M. Brigham. 2007. Torpor in an African caprimulgid, the freckled nightjar Caprimulgus tristigma. L Avian Biol 38:261-266.

McKechnie A.E. and B.G. Lovegrove. 2002. Avian facultative hypothermic responses: a review. Condor 104:705-724.

Munro D., D.W. Thomas, and M.M. Humphries. 2005. Torpor patterns of hibernating eastern chipmunks Tamias striatus vary in response to the size and fatty acid composition of food hoards. L Anim Ecol 74:692-700.

Refinetti R. 1997. The effects of ambient temperatures on the body temperature rhythms of rats, hamsters, gerbils and tree shrews. I Therm Biol 22:281-284.

Schmid J. 1996. Oxygen consumption and torpor in mouse lemurs (Microcebus murinus and M. myoxinus): preliminary results of a study in western Madagascar. Pp. 47-54 in F. Geiser, A.J. Hulbert, and S.C. Nicol, eds. Adaptations to the Cold: Tenth International Hibernation Symposium. University of New England Press, Armidale.

- 2000. Daily torpor in the gray mouse lemur (Microcebus murinus) in Madagascar: energetic consequences and biological significance. Oecologia 123:175-183.

Schmid J., T. Ruf, and G. Heldmaier. 2000. Metabolism and temperature regulation during daily torpor in the smallest primate, the pygmy mouse lemur (Microcebus myoxinus) in Madagascar. L Comp Physiol B 170:59-68.

Solick D.I. and R.M.R. Barclay. 2006. Thermoregulation and roosting behaviour of reproductive and nonreproductive female western long-eared bats (Myotis evotis) in the Rocky Mountains of Alberta. Can J Zool 84:589-599.

Song X. and F. Geiser. 1997. Daily torpor and energy expenditure in Sminthopsis macroura: interactions between food and water availability. Physiol Zool 70:331-337.

Song X., G. Körtner, and F. Geiser. 1998a. Temperature selection and use of torpor by the marsupial Sminthopsis macroura. Phvsiol Behav 64:675-682.

- 1998b. Thermal relations of metabolic rate reduction in a hibernating marsupial. Am J Physiol 273:R2097-R2104.

Steiger R. 1992. Energiehaushalt im Winterschlaf vom Goldmantelziesel (Spermophilus lateralis) vom Siebenschläfer (Glis glis). Diploma thesis. Philipps-Universität Marburg.

Turbill C. 2006. Thermoregulatory behavior of tree-roosting chocolate wattled bats (Chalinolobus morio) during summer and winter. L Mammal 87:318-323.

Turbill C., G. Körtner, and F. Geiser. 2003. Natural use of heterothermy by a small, tree-roosting bat during summer. Physiol Biochem Zool 76:868-876.

Wang L.C.H. 1978. Energetic and field aspects of mammalian torpor: the Richardson's ground squirrel. Pp. 109-145 in L.C.H. Wang and J.W. Hudson, eds. Strategies in Cold: Natural Torpidity and Thermogenesis. Academic Press, New York.

Wang L.C.H. and J.W. Hudson. 1970. Some physiological aspects of temperature regulation in the normothermic and torpid hipsid pocket mouse, Perognathus hispidus. Comp Biochem Physiol 32:275-293.

Warnecke L., P.C. Withers, E. Schleucher, and S.K. Maloney. 2007. Body temperature variation of free-ranging and captive southern brown bandicoots Isodon obesulus (Marsupialia: Peramelidae). L Therm Biol 32:72-77.

Westman W. and F. Geiser. 2004. The effect of metabolic fuel availability on thermoregulation and torpor in a marsupial hibernator. I Comp Physiol B 174:49-57.

Willis C.K.R. and R.M. Brigham. 2003. Defining torpor in freeranging bats: experimental evaluation of external temperature-sensitive radiotransmitters and the concept of active temperature. L Comp Physiol B 173:379-389.

Willis C.K.R., R.M. Brigham, and F. Geiser. 2006. Deep, prolonged torpor by pregnant free-ranging bats. Naturwissenschaften 93:80-83.

Willis C.K.R. and C.E. Cooper. Forthcoming. Techniques for studying thermoregulation and thermal biology in bats. In T.H. Kunz and S. Parsons, eds. Ecological and Behavioral Methods for the Study of Bats. Johns Hopkins University Press, Baltimore.

Willis C.K.R., A. Goldzieher, and F. Geiser. 2005a. A noninvasive method for quantifying patterns of torpor and activity under semi-natural conditions. I Therm Biol 30:551556.

Willis C.K.R., J.E. Lane, E.T. Liknes, D.L. Swanson, and R.M. Brigham. 2005b. Thermal energetics of female big brown bats (Eptesicus fuscus). Can I Zool 83:871-879.

Wilz M. and G. Heldmaier. 2000. Comparison of hibernation, estivation and daily torpor in the edible dormouse, Glis glis. L Comp Phvsiol B 170:511-521.

Withers P.C. 1992. Comparative Animal Physiology. Saunders College Publishing, Fort Worth, TX.

Zar J.H. 1999. Biostatistical Analysis. 4th ed. Prentice Hall, Upper Saddle River, NJ. 